\title{
Correction to: Influenza vaccination effectiveness for people aged under 65 years in Japan, 2013/ 2014 season: application of a doubly robust method to a large-scale, real-world dataset
}

Natsumi Shibata', Shinya Kimura ${ }^{2}$, Takahiro Hoshino ${ }^{3}$ and Hisashi Urushihara ${ }^{*}$

\section{Correction to: BMC Infect Dis}

https://doi.org/10.1186/s12879-019-4186-x

After publication of the original article [1], in Table 1, in the second and third column, "Vacnee" and "Non-vacnee" should be replaced with "Vaccinee" and "Non-vaccinee".

The original article has been corrected.

The publisher apologies for the inconvenience.

\section{Author details}

'Department of Drug Development and Regulatory Science, Faculty of Pharmacy, Keio University, 1-5-30 Shibakoen, Minato-ku, Tokyo 105-8512, Japan. ${ }^{2} J a p a n$ Medical Data Center Co., Ltd, Sumitomo Shibadaimon Building, 12F, 2-5-5 Shibadaimon, Minato-ku, Tokyo 105-0012, Japan. ${ }^{3}$ Department of Economics, Faculty of Economics, Keio University, 2-15-45 Mita, Minato-ku, Tokyo 108-8345, Japan.

Received: 15 July 2019 Accepted: 15 July 2019

Published online: 12 August 2019

\section{Reference}

1. Shibata $N$, et al. Influenza vaccination effectiveness for people aged under 65 years in Japan, 2013/ 2014 season: application of a doubly robust method to a large-scale, real-world dataset. BMC Infect Dis. 2019;19:586. https://doi.org/10.1186/s12879-019-4186-x.

\footnotetext{
* Correspondence: urushihara.hisashi@keio.jp

${ }^{1}$ Department of Drug Development and Regulatory Science, Faculty of

Pharmacy, Keio University, 1-5-30 Shibakoen, Minato-ku, Tokyo 105-8512,

Japan

Full list of author information is available at the end of the article
}

(c) The Author(s). 2019 Open Access This article is distributed under the terms of the Creative Commons Attribution 4.0 International License (http://creativecommons.org/licenses/by/4.0/), which permits unrestricted use, distribution, and reproduction in any medium, provided you give appropriate credit to the original author(s) and the source, provide a link to the Creative Commons license, and indicate if changes were made. The Creative Commons Public Domain Dedication waiver (http://creativecommons.org/publicdomain/zero/1.0/) applies to the data made available in this article, unless otherwise stated. 